\title{
Estimation of areal precipitation in the Qilian Mountains based on a gridded dataset since 1961
}

\author{
QIANG Fang, 'ZHANG Mingjun, WANG Shengjie, LIU Yangmin, \\ REN Zhengguo, ZHU Xiaofan \\ College of Geography and Environmental Science, Northwest Normal University, Lanzhou 730070, China
}

\begin{abstract}
Based on a $0.5^{\circ} \times 0.5^{\circ}$ daily gridded precipitation dataset and observations in meteorological stations released by the National Meteorological Information Center, the interannual variation of areal precipitation in the Qilian Mountains during 1961-2012 is investigated using principal component analysis (PCA) and regression analysis, and the relationship between areal precipitation and drought accumulation intensity is also analyzed. The results indicate that the spatial distribution of precipitation in the Qilian Mountains can be well reflected by the gridded dataset. The gridded data-based precipitation in mountainous region is generally larger than that in plain region, and the eastern section of the mountain range usually has more precipitation than the western section. The annual mean areal precipitation in the Qilian Mountains is $724.9 \times 10^{8} \mathrm{~m}^{3}$, and the seasonal means in spring, summer, autumn and winter are $118.9 \times 10^{8} \mathrm{~m}^{3}, 469.4 \times 10^{8} \mathrm{~m}^{3}, 122.5 \times 10^{8} \mathrm{~m}^{3}$ and $14.1 \times 10^{8} \mathrm{~m}^{3}$, respectively. Summer is a season with the largest areal precipitation among the four seasons, and the proportion in summer is approximately $64.76 \%$. The areal precipitation in summer, autumn and winter shows increasing trends, but a decreasing trend is seen in spring. Among the four seasons, summer have the largest trend magnitude of $1.7 \times 10^{8} \mathrm{~m}^{3} \cdot \mathrm{a}^{-1}$. The correlation between areal precipitation in the mountainous region and dry-wet conditions in the mountains and the surroundings can be well exhibited. There is a negative correlation between drought accumulation intensity and the larger areal precipitation is consistent with the weaker drought intensity for this region.
\end{abstract}

Keywords: gridded dataset; areal precipitation; principal component analysis; Qilian Mountains

\section{Introduction}

The global average surface air temperature shows an increasing trend by $0.5-1.3^{\circ} \mathrm{C}$ from 1951 to 2010 (Stocker et al., 2013), and the warming in arid region is usually more sensitive (Li et al., 2012). A general trend of transformation from warm dry and warm wet has been evidenced in the arid northwestern China since the late 1980s and early 1990s, which is

Received: 2015-07-29 Accepted: 2015-08-30

Foundation: National Natural Science Foundation of China, No.41461003; National Basic Research Program of China (973Program), No.2013CBA01801

Author: Qiang Fang (1987-), MS Candidate, specialized in global change and sustainable development.

E-mail: geoqiangfang@126.com

"Corresponding author: Zhang Mingjun, Professor, E-mail: mjzhang2004@163.com 
shown as increasing precipitation and decreasing drought event (Shi et al., 2007), but recent studies indicate that the drying trend still exists in some regions (e.g., Ma et al., 2003; Zhang et al., 2010). The Qilian Mountains lies at the margin of the Tibetan Plateau, and many inland rivers (including Shiyang River, Heihe River and Shule River) in the arid northwestern China originate from the alpine regions (Zhang et al., 2007). The sustainable development of oasis cities in Hexi Corridor is greatly affected by the water resources from the Qilian Mountains (Zhang et al., 2014; Zhang et al., 2008). The interannual and seasonal variation of precipitation in the Qilian Mountains is a hot topic for climate change research in this region.

As the total volume of precipitation within a domain, areal precipitation, is an important parameter in hydrological studies (Yang et al., 2006), in quantization of hydrological process, precipitation is usually expressed as water volume (i.e., areal precipitation) for a region, and areal precipitation is also an important input in numerical modeling of meteorological and hydrological studies (Cole et al., 2008). To accurately estimate areal precipitation in a specific region, many approaches have been yielded in the past years (e.g., Johansson and Chen, 2005; Leonhardt et al., 2014; Allen and Degaetano, 2005; Johansson and Chen, 2003), including spatial interpolation, multiple linear regression and remote sensing. Based on the spatial interpolation of GIS (geographic information system) technique, the distribution of precipitation can be calculated with the assistance of altitude (e.g., Zhang, 2001; Shi et al., 2008). The multiple regression methods with variables of altitude and other geographic parameters are also used to estimate the spatial pattern of precipitation (e.g., Zhao et al., 2013). In addition, remote sensing inversion is also widely applied in precipitation in the past decade (e.g., Zhang et al., 2013; Shen et al., 2010), although the satellite-observed period is usually limited (compared with the in-situ meteorological records).

The various approaches exist in calculating areal precipitation, but the accuracy of estimation is greatly related with the in-situ meteorological observations. To remove the influence of uneven distribution of observation stations, it is an effective way to calculate areal precipitation by using a high-resolution gridded precipitation dataset. Although a series of monthly or daily precipitation dataset have been released by many research institutes, the precision of these datasets still need to be further evaluated (Hewitson and Crane, 2005). In 2012, a gridded daily precipitation dataset with a resolution $0.5^{\circ} \times 0.5^{\circ}$ (V2.0) in China was released by National Meteorological Information Center (NMIC) of China Meteorological Administration (Zhao et al., 2014). In the past years, this dataset has been widely applied in meteorological assessments of mean precipitation and its extremes (e.g., Ren et al., 2015; Wang et al., 2013; Dong et al., 2014), and is considered to be suitable to describe the spatial distribution and seasonal variation of precipitation in China.

Due to complex terrain in the Qilian Mountains, the existing in-situ meteorological observation network is still too limited to cover the entire vertical landscape of the alpine regions (Jia, 2012), and areal precipitation directly estimated using measured data may underestimate precipitation to some degree. In this study, the gridded daily precipitation dataset released by NMIC is applied to the Qilian Mountains, and the long-term changes and seasonal variation of areal precipitation for this region are assessed. In addition, the relationship between areal precipitation and drought events in the Qilian Mountains and the surroundings are also studied. This paper aims to provide scientific basis to assess the regional water resource in the Qilian Mountains and its influence on downstream oases, and also present an 
approach to practically calculate areal precipitation on a large scale.

\section{Data and methods}

\subsection{Study area}

The Qilian Mountains consist of a series of NW-SE trending mountain ranges lying at the northeastern margin of the Tibetan Plateau with altitudes mostly over $4000 \mathrm{~m}$. The length of the mountains from east to west is approximately $850 \mathrm{~km}$, and the width from south to north is approximately $250-400 \mathrm{~km}$. As a vital section of ancient Silk Road, the Hexi Corridor, is located on the northern slope of the Qilian Mountains, and many oasis cities are situated in the middle and lower reaches of inland rivers originated from the Qilian Mountains. Although the Hexi Corridor belongs to the arid northwestern China with scarce precipitation and high evaporation, there are a great number of modern glaciers in the high altitudes of the Qilian Mountains. During the past decades, these glaciers have significantly retreated, which greatly influences the regional hydrological processes (Tian et al., 2014; Wang et al., 2011). According to the Second Glacier Inventory of China (Liu et al., 2015), there are 2683 glaciers with an area of $1597.81 \mathrm{~km}^{2}$ and ice volume of $84.48 \pm 3.13 \mathrm{~km}^{3}$ in the Qilian Mountains (Figure 1).

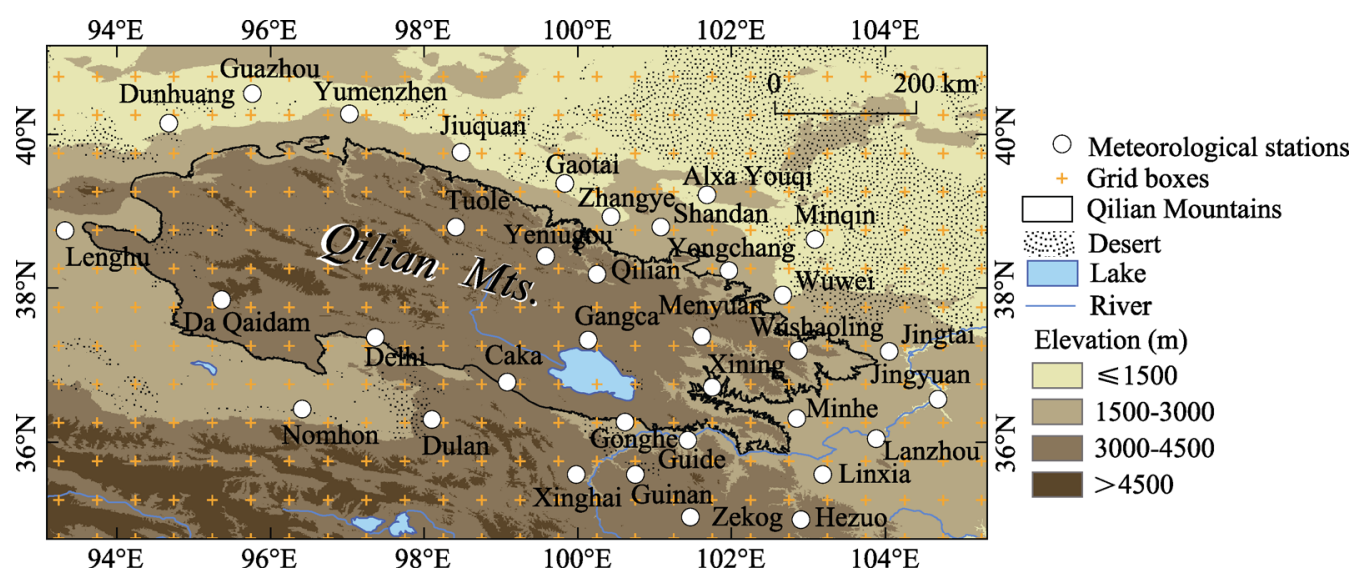

Figure 1 Distribution of observation stations and grid boxes around the Qilian Mountains

\subsection{Data}

In this study, the gridded data (China Ground Precipitation $0.5^{\circ} \times 0.5^{\circ}$ Grid Dataset V2.0) is provided by the National Meteorological Information Center (NMIC). This gridded dataset assimilated the observed daily precipitation in 2474 national meteorological stations across China during the past decades, and the initial data were strictly checked by NMIC. In order to eliminate the influence of elevation, a method of Thin Plate Smoothing Spines (TPS) in ANUSPLIN was used, and the precipitation data was interpolated to $0.5^{\circ} \times 0.5^{\circ}$ grids. More details of the structure for this dataset were introduced by Zhao et al. (2014). In this study, a total of 406 grid boxes in the Qilian Mountains and the surroundings during 1961-2012 are selected, and 86 grid boxes are within the mountain region.

Based on the standards of the consecutiveness and the longest time interval, 35 national 
meteorological stations in the Qilian Mountains and the surroundings (within $100 \mathrm{~km}$ to the mountains as buffer zones) were used (Figure 1). The data of observed daily precipitation are quality controlled by NMIC. There are 9 stations in the mountain region, including Tuole (3367 m), Yeniugou (3320 m), Qilian (2787.4 m), Menyuan (2850 m), Wushaoling (3045.1 m), Caka (3087.6 m), Delhi (2981.5 m), Gangca (3301.5 m) and Da Qaidam (3173.2 m).

In addition, the regional drought data is also acquired from NMIC. A total of 12 meteorological stations with accumulative drought intensity during 1961-2012 are selected in the Qilian Mountains and the surroundings (i.e., Caka, Gangca, Gonghe, Guide, Guinan, Jingyuan, Lanzhou, Linxia, Minhe, Wushaoling, Xining and Yongchang).

\subsection{Methods}

To compare the precipitation difference between observed and gridded data, the nearest 4 grid boxes to the meteorological station are weighted using Inverse Distance Weighted (IDW) method, and then the weighted data is used to calculate the bias and correlation coefficients. The formula of the bias is given as follows:

$$
B=\frac{\overline{P_{\text {grid }}}-\overline{P_{\text {station }}}}{\overline{P_{\text {station }}}}
$$

where $\overline{P_{\text {grid }}}$ is the mean value of interpolated data, and $\overline{P_{\text {station }}}$ is the means of observed data.

Principal component analysis (PCA) is used to find the main characteristics of precipitation in the Qilian Mountains, and SPSS 19 is employed.

The accumulative drought intensity is also used in this study, which can well reflect the duration and intensity of drought events (Li et al., 2014). The formula is given as follows:

$$
I=\sum_{k} \sum_{j}\left(T_{k j}-\left.T_{k j}\right|_{c}\right)
$$

where $T_{k j}$ is specific value on the $k$ day in the station $j$, and $\left.T_{k j}\right|_{c}$ is threshold value. The value of $k$ is duration days, and $j$ is number of stations involved on the specific day.

The nonparametric Sen's method (Sen, 1968) is employed to study interannual trends of areal precipitation, and the significant levels of linear trend are examined using a Mann-Kendall test. The spatial distribution of correlation calculations are drawn using ArcGIS 9.3.

\section{Results}

\subsection{Main pattern of the gridded dataset}

As shown in Figure 2, the bias of gridded data mostly concentrates between $0 \%$ and $20 \%$, and correlation coefficients are generally larger than 0.94 . Figure $3 \mathrm{a}$ shows the spatial distribution of bias of gridded precipitation, and the bias in most regions is less than $40 \%$ (except for some stations in the western part). In Figure $3 b$, the correlation coefficients in higher altitude are usually larger than those in lower altitude. Generally, the interpolated grids in the study area can well reflect the spatial pattern of precipitation.

Figure $4 \mathrm{a}$ shows the spatial distribution of annual mean precipitation in the study area 

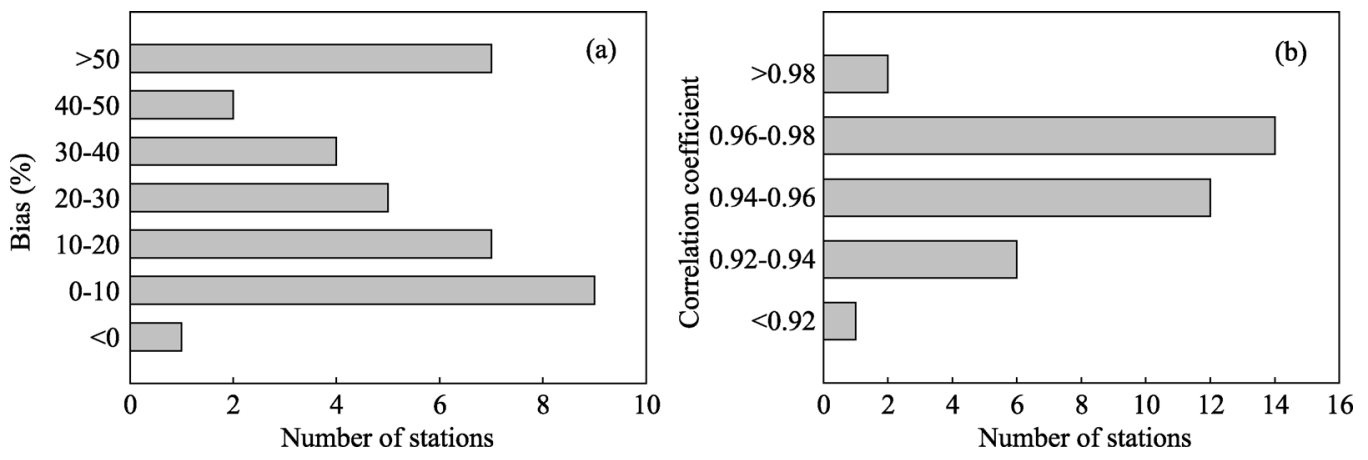

Figure 2 Numbers of stations for different ranges of bias for interpolated precipitation (a) and correlation coefficient between observed and interpolated precipitation (b) in the Qilian Mountains and the surroundings during $1961-2012$
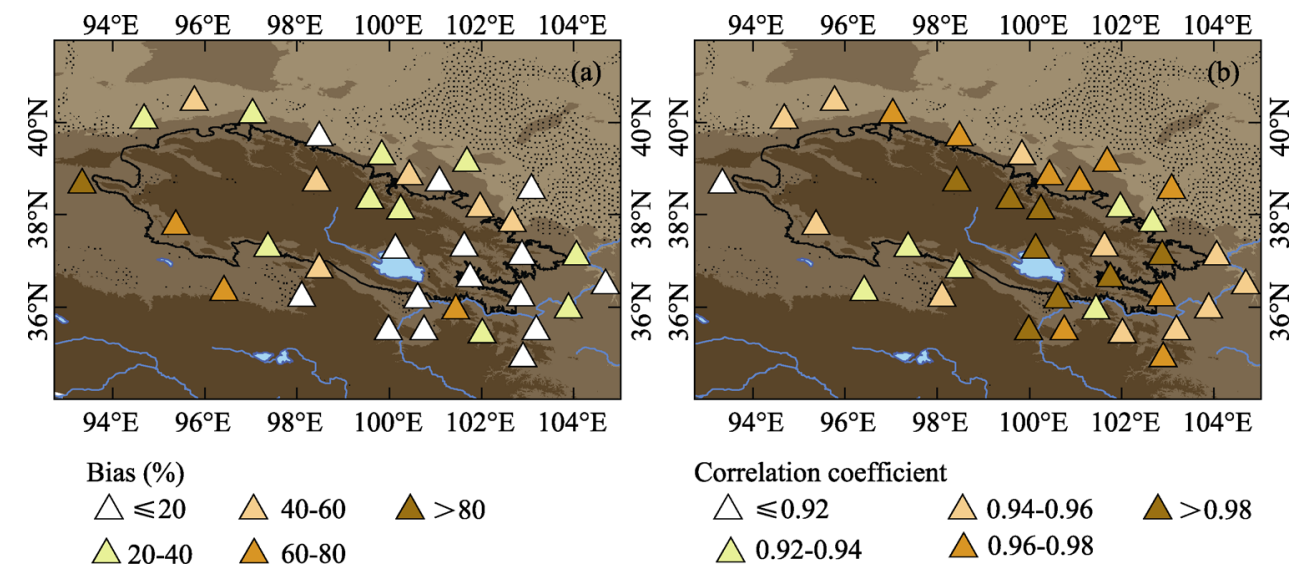

Correlation coefficient
$\triangle \leqslant 0.92$
$\triangle 0.94-0.96$
$\triangle>0.98$
$\triangle 0.92-0.94$
$\triangle 0.96-0.98$

Figure 3 Spatial distribution of bias for interpolated precipitation (a) and correlation coefficient between observed and interpolated precipitation (b) in the Qilian Mountains and the surroundings during 1961-2012

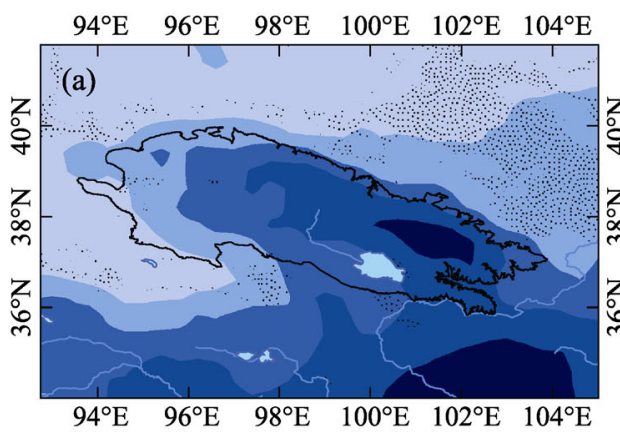

Precipitation (mm)

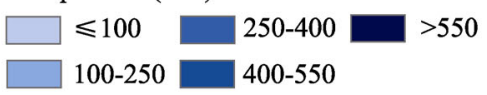

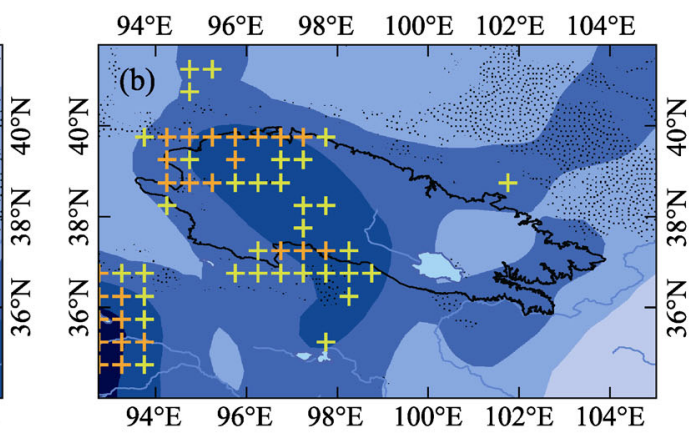

Trend $\left(\mathrm{mm} \cdot \mathrm{a}^{-1}\right)$

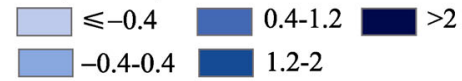

+ Significant at the 0.01 levels + Significant at the 0.05 levels

Figure 4 Spatial distribution of annual mean (a) and trend magnitude (b) of gridded precipitation in the Qilian Mountains and the surroundings during 1961-2012

during 1961-2012. The precipitation in the mountain region is generally larger than that in plain region, and the precipitation shows a decreasing trend from east to west. At the eastern section of the mountain ranges, the annual mean precipitation is larger than $550 \mathrm{~mm}$. At the 
western section, the annual precipitation is usually less than $250 \mathrm{~mm}$. During the study period, all the study area shows an increasing trend. The trend in the western part is more significant than that in the eastern part (Figure $4 \mathrm{~b}$ ). Some $11.6 \%$ and $12.8 \%$ of the grid boxes are statistically significant at the 0.01 level and 0.05 levels, respectively.

The principal component analysis (PCA) is applied to the gridded precipitation in this study, and the results are shown in Figure 5. The first principal component of annual precipitation (Figure 5a) has very similar distribution value in whole region, in which the bias only exists in the northwestern corner. The negative value zone of the second principal component (Figure 5b) is consistent with the spatial domain of the high-altitude Tibetan Plateau. The third principal component (Figure 5c) exhibits negative value in southeast and positive value in northwest, in which the negative value occurs mostly in the Qilian Mountains. The study area is jointly influenced by multiple weather regimes, including the eastern Asian monsoon, Indian monsoon and Plateau monsoon as well as Westerlies circulation in the Northern Hemisphere (Zhang et al., 2007). The third principal component may reflect the distribution of dry and wet conditions. The western part of the Qilian Mountains is greatly controlled by Westerlies circulation, and shows limited precipitation. Shown in Table 1,
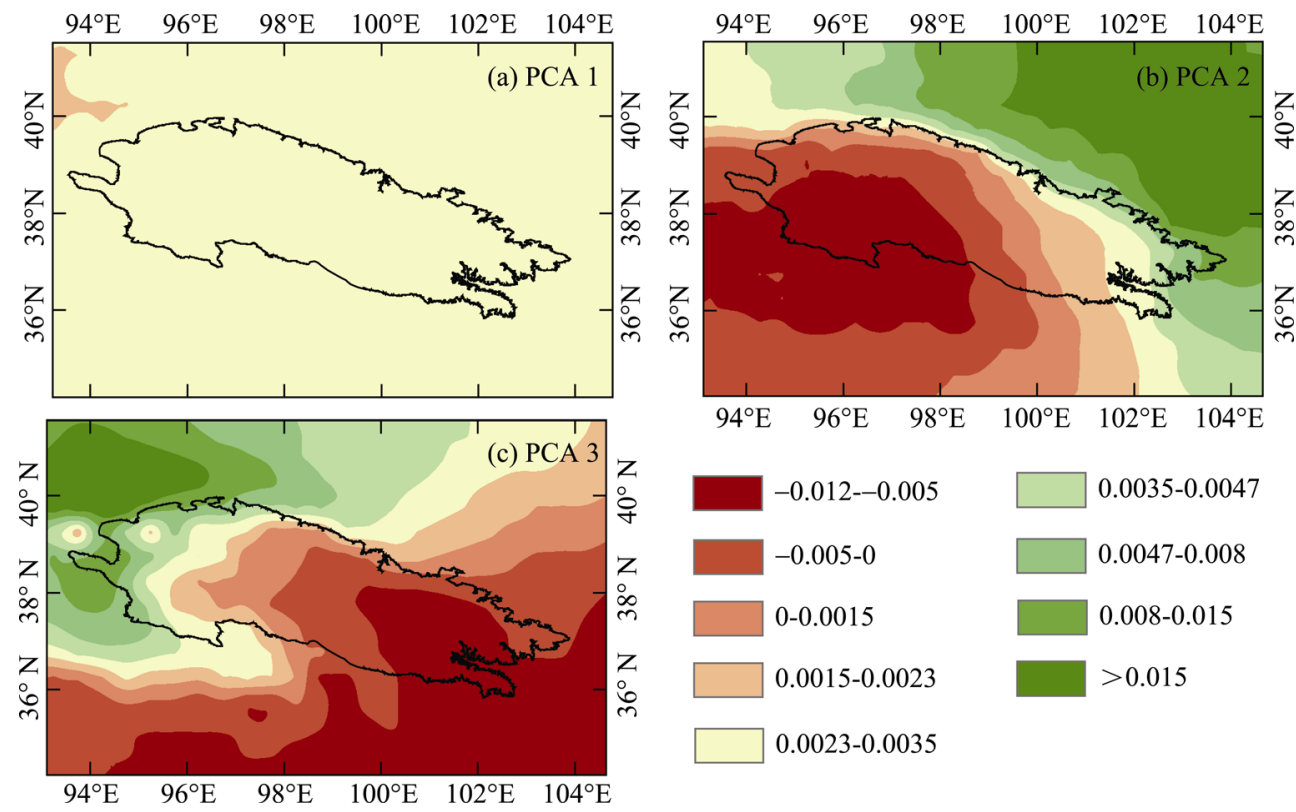

$0.0015-0.0023$

0.015

Figure 5 Spatial distribution of result for principal component analysis of gridded precipitation in the Qilian Mountains and the surroundings during 1961-2012

Table 1 Result for principal component analysis of gridded precipitation in the Qilian Mountains and the surroundings during 1961-2012

\begin{tabular}{cccc}
\hline \multirow{2}{*}{ Component } & \multicolumn{3}{c}{ Initial eigen value } \\
\cline { 2 - 4 } & Amount & Variance contribution (\%) & Accumulative (\%) \\
\hline PCA1 & 279.99 & 68.96 & 68.96 \\
PCA2 & 27.42 & 6.75 & 75.72 \\
PCA3 & 25.54 & 6.29 & 82.01 \\
\hline
\end{tabular}


the first principal component has a variance contribution of $68.89 \%$, which represents the dominant character of precipitation variation. The second and third principal components show $6.75 \%$ and $6.29 \%$ in total variance, respectively, indicating a faster convergence.

\subsection{Temporal variation of areal precipitation}

The seasonal variation of areal precipitation during 1961-2012 in the Qilian Mountains shows increasing trend in summer (Figure 6b), autumn (Figure 6c) and winter (Figure 6d) with tendency rates of $16.50 \times 10^{8} \mathrm{~m}^{3} \cdot \mathrm{a}^{-1}, 2.67 \times 10^{8} \mathrm{~m}^{3} \cdot \mathrm{a}^{-1}$ and $1.19 \times 10^{8} \mathrm{~m}^{3} \cdot \mathrm{a}^{-1}$, respectively, and a decreasing trend at $-0.17 \times 10^{8} \mathrm{~m}^{3} \cdot \mathrm{a}^{-1}$ in spring (Figure 6a). The trends in spring are statistically significant at the 0.01 levels. Generally, there is significant seasonal diversity of areal precipitation in the Qilian Mountains. The trend magnitude in summer is the largest among the four seasons, and the least trend magnitude is seen in spring.
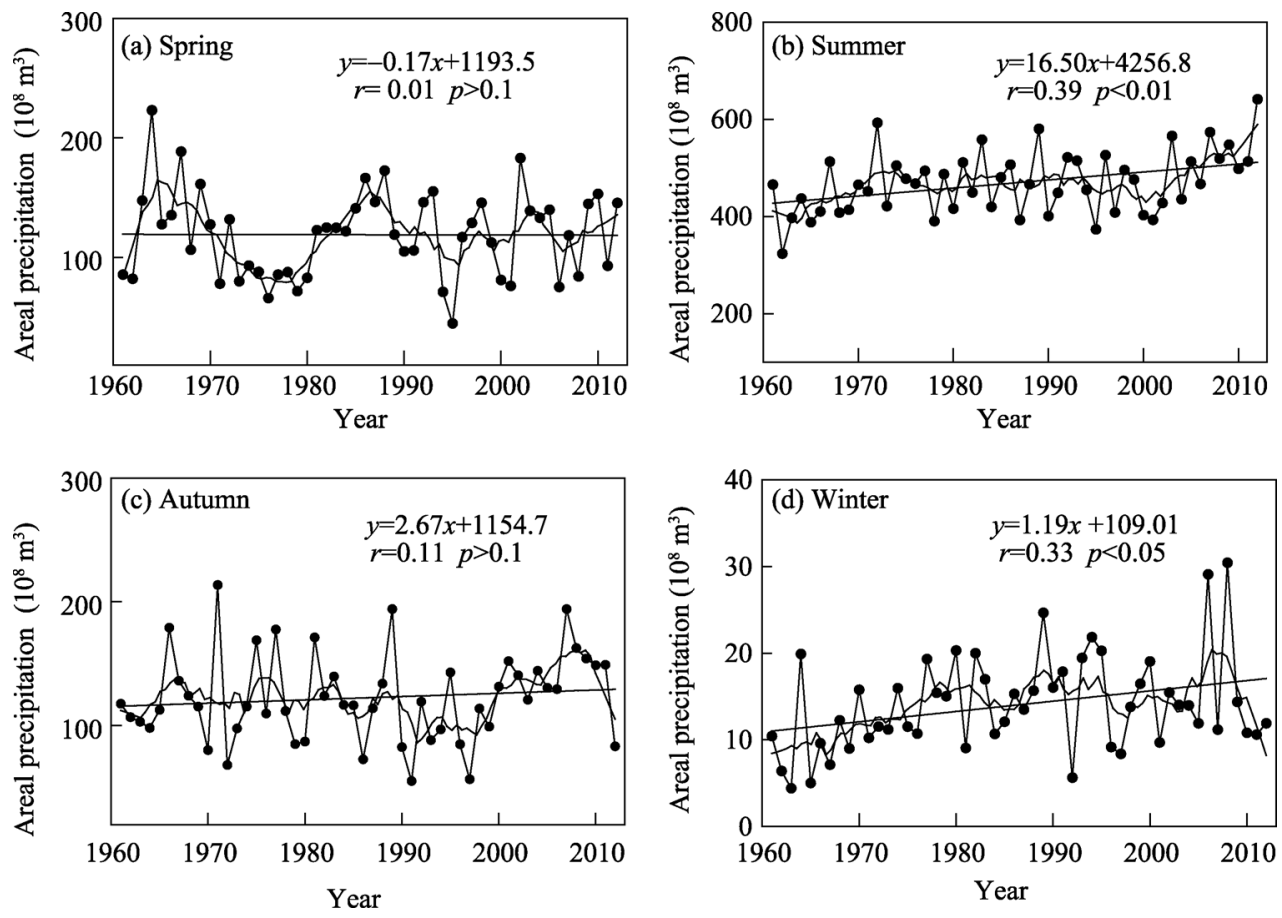

Figure 6 Interannual variation of areal precipitation in the Qilian Mountains during 1961-2012

Additionally, the areal precipitation in each season is different (Table 2). The mean annual precipitation in the past 52 years is $724.9 \times 10^{8} \mathrm{~m}^{3}$, in which the areal precipitation in spring, summer, autumn and winter are $118.9 \times 10^{8} \mathrm{~m}^{3}, 469.4 \times 10^{8} \mathrm{~m}^{3}, 122.5 \times 10^{8} \mathrm{~m}^{3}$ and $14.1 \times 10^{8}$ $\mathrm{m}^{3}$, respectively. The areal precipitation in summer shows the largest $(64.76 \%)$, and the least is in winter $(1.94 \%)$. If the study period is subdivided into two stages before and after the year 1987 (as mentioned by Shi et al., 2007), the areal precipitation amounts in each season during 1987-2012 are larger than that during 1961-1986 by $2.80 \%, 5.96 \%, 2.36 \%$ and $24.58 \%$, respectively, and annual areal precipitation during 1987-2012 is larger than during $1961-1986$ by $5.15 \%$.

The areal precipitation in each season of the Qilian Mountains has been analyzed in the 
Table 2 Decadal mean of annual and seasonal areal precipitation in the Qilian Mountains during 1961-2012

\begin{tabular}{cccccc}
\hline \multirow{2}{*}{ Decade } & \multicolumn{5}{c}{ Areal precipitation $\left(10^{8} \mathrm{~m}^{3}\right)$} \\
\cline { 2 - 6 } & Spring & Summer & Autumn & Winter & Annual \\
\hline $1961-1970$ & 138.4 & 422.2 & 117.3 & 10.0 & 687.9 \\
$1971-1980$ & 86.4 & 470.4 & 123.5 & 14.1 & 694.4 \\
$1981-1990$ & 134.4 & 476.6 & 126.5 & 15.4 & 752.9 \\
$1991-2000$ & 110.7 & 462.3 & 98.9 & 15.2 & 687.0 \\
$2001-2010$ & 124.6 & 494.0 & 147.8 & 16.1 & 782.5 \\
$1961-1986$ & 117.3 & 455.8 & 121.1 & 12.5 & 706.7 \\
$1987-2012$ & 120.5 & 483.0 & 124.0 & 15.6 & 743.1 \\
$1961-2012$ & 118.9 & 469.4 & 122.5 & 14.1 & 724.9 \\
Percentage (\%) & 16.40 & 64.76 & 16.90 & 1.94 & \\
\hline
\end{tabular}

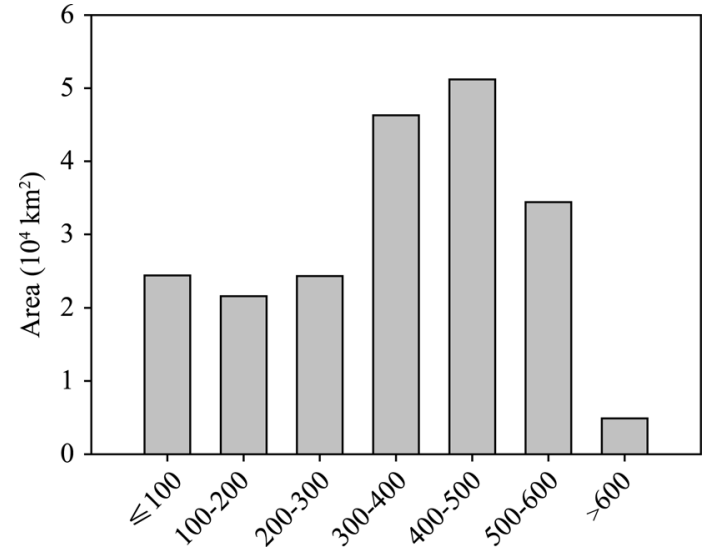

Figure 7 Area distributions for each grade of annual precipitation in the Qilian Mountains

$\mathrm{km}^{2}$, which are $33.9 \%$ in the total area. above section, while there is spatial diversity in the area for each grade in annual precipitation (Figure 7). The gridded precipitation in this study has been divided into 7 grades. In most areas, the annual precipitation is between $300 \mathrm{~mm}$ and 600 $\mathrm{mm}$, in which the areas with precipitation of $300-400 \mathrm{~mm}, \quad 400-500 \mathrm{~mm}$ and $500-600 \mathrm{~mm}$ are $4.63 \times 10^{4} \mathrm{~km}^{2}(22.3 \%)$, $5.12 \times 10^{4} \mathrm{~km}^{2}(24.7 \%)$ and $3.44 \times 10^{4} \mathrm{~km}^{2}$ $(16.6 \%)$, respectively. Precipitation above $600 \mathrm{~mm}$ is occupied to $0.49 \times 10^{4} \mathrm{~km}^{2}$ (2.3\% in total area), while precipitation below $300 \mathrm{~mm}$ is occupied to $7.03 \times 10^{4}$

\subsection{Relationship between areal precipitation and drought intensity}

Drought is a phenomenon which moisture is anomalous short with unbalanced precipitation and evapotranspiration, and widely occurs in Northwest China (Huang et al., 2011). In this section, the relationship between areal precipitation anomaly and drought accumulation intensity is analyzed. The percentage of areal precipitation is applied, and are divided into 8-25 (Larger), $-8-8$ (Normal) and -25 to -8 (Less). In order to reflect the relationship between areal precipitation and drought, grades of drought accumulation intensity are also divided into -38 to -28 (stronger drought), -28 to -18 (drought), and -18 to -8 (weaker drought) in Figure 8.

In different percentages of annual areal precipitation, the percentage of stations of drought accumulation intensity demonstrates weaker (75\%), which is larger than stronger drought accumulation intensity (17\%). From weaker drought accumulation intensity, stations of larger percentage for annual areal precipitation are much more. In stronger stations, less percentage for annual areal precipitation are larger. Generally, there is negative correlation be- 
tween drought accumulation intensity and areal precipitation, in which more precipitation exists in weaker drought intensity and precipitation can well reflect drought accumulation intensity.

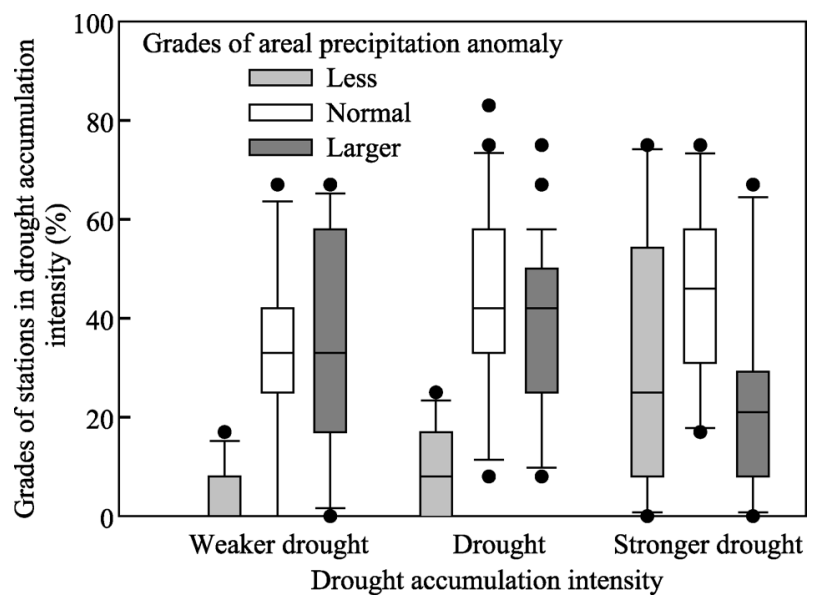

Figure 8 Relationship between areal precipitation anomaly and drought accumulation intensity in the Qilian Mountains and the surroundings

\section{Discussion}

Areal precipitation is an important hydrological parameter, and has been calculated by using different methods across the world (e.g., Johansson and Chen, 2005; Leonhardt et al., 2014; Allen and Degaetano, 2005; Johansson and Chen, 2003), but uneven spatial distribution of observation stations greatly influenced the accuracy of estimated areal precipitation. To find a practical method in related studies, the procedure based on a gridded precipitation dataset released by NMIC is recommended in this study. Compared with spatial interpolation methods (usually operated in GIS) and multiple regressions using geographical parameters, the procedure in this study is much more convenient and can be widely used in different field. In addition, this method also has longer time series (dated back to the 1960s) than the inversion method of remote sensing.

The fluctuation of precipitation can reflect regional dry and wet conditions (Ma et al., 2003; Huang et al., 2015). In the Qilian Mountains, the study of the relationship between areal precipitation and drought event can deepen the knowledge of climate change in arid northwestern China and the Tibetan Plateau. In this paper, the drought accumulation intensity is studied, and the results are useful to understand the hydrological process and regional drought events, especially in the Hexi oasis.

\section{Conclusions}

A gridded dataset is used to calculate areal precipitation in the Qilian Mountains during the past decades, and the spatial distribution and interannual variation of areal precipitation in the study area are studied. The conclusions are given as follows:

(1) The gridded dataset can well reflect precipitation pattern in the Qilian Mountains and the surroundings. The precipitation in mountainous region is generally larger than that in 
plain region, and the eastern section of the mountain range usually has more precipitation than the western section.

(2) The annual mean value of areal precipitation in the Qilian Mountains is $724.9 \times 10^{8} \mathrm{~m}^{3}$, in which the areal precipitation in spring, summer, autumn, and winter are $118.9 \times 10^{8} \mathrm{~m}^{3}$, $469.4 \times 10^{8} \mathrm{~m}^{3}, 122.5 \times 10^{8} \mathrm{~m}^{3}$ and $14.1 \times 10^{8} \mathrm{~m}^{3}$, respectively. The tendency rate of areal precipitation in summer is the largest among the four seasons, and the lowest trend magnitude is seen in spring.

(3) There is negative correlation between drought accumulation intensity and areal precipitation, in which more precipitation is consistent with lower drought intensity.

\section{References}

Allen R J, Degaetano A T, 2005. Considerations for the use of radar-derived precipitation estimates in determining return intervals for extreme areal precipitation amounts. Journal of Hydrology, 315: 203-219.

Cole S J, Moore R J, 2008. Hydrological modelling using raingauge- and radar-based estimators of areal rainfall. Journal of Hydrology, 358(3/4): 159-181.

Dong Lei, Zhang Mingjun, Wang Shengjie et al., 2014. Extreme precipitation events in arid areas in northwest China based on gridded data. Journal of Natural Resources, 29(12): 2048-2057. (in Chinese)

Hewitson B C, Crane R G, 2005. Gridded area-averaged daily precipitation via conditional interpolation. Journal of Climate, 18(1): 41-57.

Huang Xiaoyan, Zhang Mingjun, Jia Wenxiong et al., 2011. Variation of surface humidity and its influential factors in Northwest China. Advances in Water Science, 22(2): 151-159. (in Chinese)

Jia Wenxiong, 2012. Temporal and spatial changes of precipitation in Qilian Mountains and Hexi Corridor during 1960-2009. Acta Geographica Sinica, 67(5): 631-644. (in Chinese)

Johansson B, Chen D, 2003. The influence of wind and topography on precipitation distribution in Sweden: Statistical analysis and modeling. International Journal of Climatology, 23(12): 1523-1535.

Johansson B, Chen D, 2005. Estimation of areal precipitation for runoff modeling using wind data: A case study in Sweden. Climate Research, 29(1): 53-61.

Leonhardt G, Sun S, Rauch W et al., 2014. Comparison of two model based approaches for areal rainfall estimation in urban hydrology. Journal of Hydrology, 511(4): 880-890.

Li Baofu, Chen Yaning, Shi Xun, 2012. Why does the temperature rise faster in the arid region of northwest China. Journal of Geophysical Research: Atmospheres, 117(D16): 81-81.

Li Yunjie, Ren Fumin, Li Yiping et al., 2014. A study of the characteristics of the southwestern China regional meteorological drought events during 1960-2010. Acta Meteorologica Sinica, 72(2): 266-276. (in Chinese)

Liu Shiyin, Yao Xiaojun, Guo Wanqin et al., 2015. The contemporary glaciers in China based on the second Chinese glacier inventory. Acta Geographica Sinica, 70(1): 3-16. (in Chinese)

Ma Zhuguo, Hua Lijuan, Ren Xiaobo, 2003. The extreme dry/wet events in Northern China during recent 100 years. Acta Geographica Sinica, 58(Suppl.): 69-74. (in Chinese)

Ren Zhengguo, Zhang Mingjun, Wang Shengjie et al., 2015. Changes in daily extreme precipitation events in South China from 1961 to 2011. Journal of Geographical Sciences, 2015, 25(1): 58-68.

Sen P K, 1968. Estimates of the regression coefficient based on Kendall's tau. Journal of the American Association, 39: 1379-1389.

Shen Yan, Xiong Anyuan, Wang Ying et al., 2010. Performance of high-resolution satellite precipitation products over China. Journal of Geophysical Research: Atmospheres, 115(D2): 355-365.

Shi Yafeng, Shen Yongping, Kang Ersi et al., 2007. Recent and future climate change in northwest China. Climatic Change, 80(3/4): 379-393.

Shi Yuguang, Sun Zhaobo, Yang Qing, 2008. Characteristics of area precipitation in Xinjiang region with its variations. Journal of Applied Meteorological Science, 19 (3): 325-332. (in Chinese) 
Stocker T F, Qin D, Plattner G-K et al., 2013. Climate Change 2013: The Physical Science Basis. Cambridge: Cambridge University Press.

Tian Hongzhen, Yang Taibao, Liu Qinping, 2014. Climate change and glacier area shrinkage in the Qilian Mountains, China, from 1956 to 2010. Annals of Glaciology, 55(66): 187-197.

Wang Puyu, Li Zhongqin, Gao Wenyu, 2011. Rapid shrinking of glaciers in the Middle Qilian Mountain region of Northwest China during the last 50 years. Journal of Earth Science, 22(4): 539-548.

Wang Shengjie, Zhang Mingjun, Sun Meiping et al., 2013. Changes in precipitation extremes in alpine areas of the Chinese Tianshan Mountains, Central Asia, 1961-2011. Quaternary International, 311(11): 97-107.

Wei Jie, Ma Zhuguo, 2003. Comparison of palmer drought severity index, percentage of precipitation anomaly and surface humid index. Acta Geographica Sinica, 58(Suppl.): 117-124. (in Chinese)

Yang Qing, Sun Churong, Shi Yuguang et al., 2006. Estimation of areal precipitation series and its relation to runoff in Aksu river basin. Acta Geographica Sinica, 61(7): 697-704. (in Chinese)

Zhang Liang, Zhang Qiang, Feng Jianying et al., 2014. A study of atmospheric water cycle over the Qilian Mountains (I): Variation of annual water vapor transport. Journal of Glaciology and Geocryology, 36(5): 1079-1091. (in Chinese)

Zhang Qiang, Yu Yaxun, Zhang Jie, 2008. Characteristics of water cycle in the Qilian Mountains and the oases in Hexi inland river basins. Journal of Glaciology and Geocryology, 30(6): 907-913. (in Chinese)

Zhang Qiang, Zhang Cunjie, Bai Huzhi et al., 2010. New development of climate change in northwest China and its impact on arid environment. Journal of Arid Meteorology, 28(1): 1-7. (in Chinese)

Zhang Qiang, Zhang Jie, Sun Guowu et al., 2007. Research on atmospheric water-vapor distribution over Qilianshan Mountains. Acta Meteorologica Sinica, 65(4): 633-643. (in Chinese)

Zhang Renhe, 2001. Relations of water vapor transports from Indian monsoon with those over East Asia and the summer rainfall in China. Advances in Atmospheric Sciences, 18(5): 1005-1017.

Zhang Zhixian, Zhang Qiang, Zhang Qingyun et al., 2013. Radar quantitative precipitation inversion and its application to areal rainfall estimation in the northeastern marginal areas of the Tibetan Plateau. Journal of Glaciology and Geocryology, 35(3): 621-629. (in Chinese)

Zhao Ling, Yang Qing, An Shazhou, 2013. Distribution and change characteristics of areal precipitation in Tianshan Mountains during 1961-2010. Desert and Oasis Meteorology, 7(2): 20-24. (in Chinese)

Zhao Yufei, Zhu Jiang, Xu Yan, 2014. Establishment and assessment of the grid precipitation datasets in China for recent 50 years. Journal of the Meteorological Sciences, 34(4): 414-420. (in Chinese) 